\title{
Identifying barriers to improving the process of discharging patients from hospital
}

Ann-Marie Cannaby Division of Medicine for the Elderly, Leicester University, Stuart Graeme Parker Division of Medicine for the Elderly, University of Leicester, Francine Cheater and Richard Baker Clinical Governance Research and Development Unit, Department of General Practice and Primary Health Care, University of Leicester, Leicester General Hospital, Leicester LE5 4PW, UK,

\begin{abstract}
Objective: To identify the barriers to successful discharge practices in a general hospital medical service.

Design: Focus groups with health professionals and in depth interviews with patients were used to identify and explore themes arising from the concept of a good discharge. Thematic analysis was undertaken to identify and link the concepts highlighted.

Subjects: Four focus groups (four to ten participants) and ten in depth interviews were conducted. Purposive sampling was used to capture a full range of views.

Main outcome measures: Themes arising from the focus groups and interviews were analysed to examine barriers to effective discharge practice.

Results: Five major themes emerged from the focus group data including; 1) Communication, 2) Teamwork and Roles, 3) The process of discharge and co-ordination 4) Resources, and 5) Time. Patients discussed their experiences, concerns and lack of knowledge, of the discharge process.

Conclusion: The barriers to influencing the discharge process were shown to be complex and interrelated. The way, in which teams work together is an important factor, which appears not to have been addressed in research into discharge interventions. No single strategy or intervention is likely to be successful in changing discharge practice. Future research to improve discharge should focus on combinations of strategies that target local barriers at the level of the individual, team and organization.
\end{abstract}

Key words: discharge care; hospital discharge

\section{Introduction}

Discharge of patients from hospital is an important quality issue for acute and community health and social care, and for patients and their carers $(\mathrm{DoH}$, 1994). The potential problems faced by patients when discharged from hospital were identified over 30 years ago, but still remain unresolved (Madsen, 1965; Skeet, 1970; Roberts, 1975). Poor discharge structure and process can lead to poor outcomes (Closs and Tierney, 1993), including inadequately informed and therefore dissatisfied patients and

\footnotetext{
Address for correspondence: Ann-Marie Cannaby, Department of General Practice and Primary Health Care, Leicester University, Leicester, UK. Email: ann-marie.cannaby@uni-tr.nhs.uk
}

carers (McWilliam and Sangster, 1994), lack of coordination of care (Jewel, 1993) and increased lengths of stay (Farren, 1991) and readmission (Naylor, 1990). To improve the quality of discharge care, identification of the specific obstacles need to be identified, to ensure specific tailored interventions can be used. This study identifies the barriers in one setting to the process of a 'good' discharge.

A successful discharge depends on detailed information being passed between professionals and between the professional and the patient and carer (DoH, 1989). However, communication is often poor, with patients not being consulted about their own discharge arrangements (Bull, 1994; Congdon, 1994). Failures in communication between professionals in the acute sector and $10.1191 / 1463423603 p c 122$ oa 
across the primary and secondary interface result in community staff having little information about patients (Williams and Fitton, 1991; Meara et al., 1992). Community staff perceive that they are rarely involved in decision-making (Tierney et al., 1993).

Planning should enable adequate time for those involved in discharge planning to communicate and participate in decision making (DoH, 1992). Hasty discharge planning produces dissatisfaction for patients and professionals alike (Harding and Modell, 1989).

Comprehensive discharge planning that begins on admission and is standardized in approach (Naylor, 1990; Haddocks, 1994) has reduced cost and length of stay (Sytrborn, 1995) and has resulted in improved quality of discharge. The potential benefits of the continuation of care across the primary/secondary interface through the work of by employing discharge/case managers have been investigated. Mamon et al. (1992) showed a significant reduction in unmet health and social needs (e.g., home help), although other studies found no improvements in the provision of services (Lockery et al., 1994).

Patients perceive that discharge planning is fragmented and nurses themselves are often uncertain about their role. The co-ordination of the team is problematic as team roles may not have been defined (Lowenstein and Hoff, 1994). Discharge planning is time consuming and the hidden work of organizing discharge in a large bureaucracy means that the process of planning is not always prioritized (MacWilliam and Wong, 1994).

Our own experience showed that the introduction of a model discharge procedure was a complex and difficult task, which had only limited impact on the experience of patients and carers (Peet et al., 1997). The barriers to introducing good discharge practice may need to be identified and overcome before major changes can be achieved. This preliminary work considers both professionals' and patients' perspectives of the barriers to the discharge process. By identifying barriers, future research into specific interventions can be conducted to address those barriers that are most important and most common.

The aim of the study was, therefore, to identify barriers to implementing the discharge process in an acute hospital and the local community services.

The specific objectives of the study were to:
- Identify the perceptions of professionals and patients about barriers in the discharge process;

- Develop greater understanding of the barriers to improving discharge at an organisational, team and individual level.

The local research ethics committee approved the study.

\section{Methods}

\section{Focus groups and interviews}

Focus groups were used to collect data on the perceptions of health professionals from both primary and secondary care, involved in the discharge of medical patients from hospital (Table 1). To identify the patient's perceptions, semi-structured interviews in patients' own homes were undertaken after they had been discharged from hospital. Focus groups with patients were not undertaken because of the difficulties of patient immobility and transportation. In addition, a focus group setting may have inhibited some patients from discussing their experiences. Both methods were piloted and minor adjustments to the interview schedules were made.

\section{Selection of participants}

Health professionals were selected from an acute teaching hospital and a community trust in Leicestershire. The researcher aimed to ensure that a person from each professional group involved in the process of discharge planning was invited to attend each focus group. Managers in both the hospital and community trust were asked to identify professionals who were involved in organizing discharge and able to attend a focus group meeting. Representatives from nursing, medicine, social work, occupational therapy, physiotherapy, and

Table 1 Interview topics in the Focus group with professionals

What constitutes a good discharge?

Personal experience and difficulties

Co-ordination of discharge

Multi-disciplinary working

Organisational influences in improving discharge

The patient's perspective 
dietetics were approached (Table 2). Two community based and two hospital based focus groups were held. After the fourth focus group, no further groups were required as no new data emerged.

Medical patients in the acute trust were recruited for the semi-structured interviews. Purposive sampling was used to select patients. Prior to recruitment five patient categories were identified, ranging from patients requiring little assistance with discharge arrangements (category 1), to those with complex needs (category 5) enabling a range of views of the discharge experience. Patients likely to be discharged within three to four days and who had at least a 48-hour stay were identified by nursing staff. The study was explained to the patient and informed consent sought. Interviews took place between one and two weeks after discharge, and were conducted by the researcher (Cannaby) in the patients own home. Ten interviews were conducted involving four males and six females with ages ranging from 40-84yrs (mean 63.4).

\section{Analysis}

The focus groups and the interviews were audiotaped, then transcribed and the transcripts coded. There were no preset codes or categories prior to the analysis and all themes were derived directly from the data. Transcripts were sent to two members of each focus group to validate the accuracy of the transcripts. To ensure consistency of coding two focus group and two interview transcripts were checked and coded independently by a second researcher (Cheater). Inter-rater reliability checks were performed and Kappa values ranged from 0.64-0.82 indicating good levels of agreement (Miles and Huberman, 1994).

\section{Results}

\section{Focus groups}

Five major themes emerged from the focus group data, including communication, teamwork, roles/expectations, resources and time. Within these broad themes a number of barriers were identified.

\section{Communication}

\section{Communication between professionals and patients}

Giving and receiving of information was considered vital for effective discharge. However, effectiveness of communication within the multidisciplinary team was perceived as variable ( 'hit and miss'). Difficulties in communication were experienced both within organizations and across organizational boundaries. Trying to contact the appropriate professional and knowing whom to contact caused difficulties and was time consuming. District nurses said that they preferred verbal communications with the hospital staff, as this enabled them to gain more information and question nurses prior to the patient's discharge. However, since the flow of information was unreliable and not two-way, district nurses felt they lacked knowledge about patients. The use of a telephone answer machine meant that direct contact was further reduced. District nurses found that: 'there are problems with answer machines, many people talk too quickly and the information is not properly picked up' (Focus Group 2 - Participant 4, District nurse) Active attempts to obtain information were time consuming and not always fruitful. There

Table 2 Participants at focus group meetings

\begin{tabular}{|c|c|c|c|}
\hline $\begin{array}{l}\text { Focus group } 1 \\
\text { Hospital }(n=10)\end{array}$ & $\begin{array}{l}\text { Focus group } 2 \\
\text { Community }(n=4)\end{array}$ & $\begin{array}{l}\text { Focus group } 3 \\
\text { Community }(n=7)\end{array}$ & $\begin{array}{l}\text { Focus group } 4 \\
\text { Hospital }(n=10)\end{array}$ \\
\hline $\begin{array}{l}\text { Staff Nurses (3) } \\
\text { Ward manager (2) } \\
\text { Physiotherapist(1) } \\
\text { Physiotherapy assistant (1) } \\
\text { Occupational therapist (1) } \\
\text { Social worker(1) } \\
\text { Dietician(1) }\end{array}$ & $\begin{array}{l}\text { Sister (1) } \\
\text { Staff nurse (2) } \\
\text { Occupational therapist (1) }\end{array}$ & 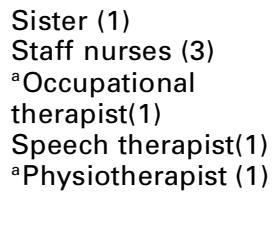 & $\begin{array}{l}\text { Consultant ( 2) } \\
\text { Ward manager (2) } \\
\text { Staff nurse (2) } \\
\text { Dietician(1) } \\
\text { Occupational therapist(1) } \\
\text { Physiotherapist(1) } \\
\text { Social worker(1) }\end{array}$ \\
\hline
\end{tabular}

a = based at community hospital 
were many examples of difficulties faced by community staff seeking information from ward staff. 'It amazes me that when I ring up for some information about that patient and there is not one nurse on the ward who can tell you anything about the patient. That's quite frightening I think' (Focus Group 2 - Participant 3, District nurse)

In all the focus groups numerous examples were given of poor communication between patients and professionals. These included nurses misunderstanding patients, language barriers and patients not being given enough information about their follow-up care. The case conference meeting was recognized as a specific multiprofessional meeting at which decisions were made. There were mixed views about the effectiveness of this forum with some staff suggesting that it was a productive meeting, whilst others commented that participation and decision making skills within the multidisciplinary team were sometimes poor. Decisions were sometimes not taken at all and individuals within the team did not feel sufficiently 'powerful' to influence decision making.

\section{Written information}

Written details and patient records caused immense frustration. The progress of patients was often recorded in several sets of records. Some professionals did not write in the medical or nursing notes, others had separate notes, which were not held on the ward. This led to repeated telephone calls in order to access the information. Some professionals were not aware if there were recommended procedures for completing records. 'I am often unsure of when and where to write things, I do write in the notes, but it is mainly in the medical notes' (Focus Group 4 - Occupational therapist). Multidisciplinary notes were regarded as a potential solution: "when we get to a point where everybody's writing on the same thing, the patient's care will be less fragmented and we'll be able to see where we're going' (Focus Group 4 Participant 1, Physiotherapist)

Hospital discharge details given to community staff were often sparse. Written communication from acute hospitals was not always comprehensive. Focus group members saw the content and the planning of discharge as the problem, rather than the structure of the form used to convey information. Focus group participants indicated that the timing of the referral of patients to other disciplines often caused confusion. Some professionals wished to have early referrals, others wanted referrals at particular times during in the patient's stay. There was consensus that late referrals caused problems for all professional groups.

\section{Team work}

Team work was one of the most prominent themes to emerge. Participants felt that their teams appeared not to have any general or discharge specific goals or purpose, and felt at times that members of their team did not value their contribution to patient care. Members of all disciplines within the focus groups could describe occasions when their opinions had not been valued. Although they were not asked which professionals they considered to be part of the discharge team, some reported they did not know the names of some of their team members. Focus group members also stated that there were no formal links between primary and secondary care teams. All groups discussed the role of the doctor in discharge planning. Doctors were seen as having the final decision about discharge and at times undermined the group's decisions. 'Consultants are the ones really making the decisions ... they come along, make decisions and they haven't actually consulted the team ... negotiations in some areas are poor, with the consultant having the final word' (Focus Group 1 - Participant 6, Physiotherapist)

Two doctors participated in one group. They felt that they had to make the decisions because at times the team 'was ineffective at making it' (Focus Group 4 - Participant 7, Doctor). Staff participation in the discharge process were discussed and the passivity of some disciplines on ward rounds and meetings was highlighted, 'sometimes the nurse on the ward round acts as a record keeper, writing down the information and not actively contributing' (Focus Group 4 - Participant 9, Doctor).

\section{Roles and expectations within the team}

The participants of the groups felt that they did not properly understand the roles and boundaries of other disciplines. The expectations of one professional group of another, for example junior doctor or community nurse, were not met because of the lack of understanding of the roles of different professional groups. One community nurse commented, 'There's a lot of ignorance actually 
because I think that the ward does not know what happens when a patient is discharged. We don't drive vans with pharmacies in the back and mattresses and wheel chairs' (Focus Group 3 - Participant 4, District staff nurse). Community nurses had an expectation that when they rang the wards they would receive details about patients. Within the community focus groups there was the recognition that unless you spoke to the patients' named nurse, obtaining information could be difficult.

Patients' expectations were referred to particularly by social workers, who felt that they were often placed in difficult situations. Other professionals did recognise the difficulties but social workers felt that patients themselves had an expectation of receiving a service that could not be guaranteed until funds were allocated.

\section{The discharge process and co-ordination}

Discharge practices varied widely and there was lack of clarity at times about what to do when. There appeared to be little standardization on how patients were prepared for discharge. Whilst there were policies and procedures, these were not always followed. Discussions about the role of coordinating discharge resulted in general agreement that the named or primary nurse should co-ordinate discharge and could liaise with occupational therapist, physiotherapists and social workers. As participant one stated: 'it's got to be said, it's nursing interventions that will expedite the discharge' (Focus group 4 - Participant 6, Staff nurse)

A suggestion that a liaison person who was jointly funded by health and social services, would ensure successful co-ordination of discharge. Nurses within the focus groups recognized that the discharge process was not consistently planned for. The importance of beginning discharge planning during the nursing assessment was reiterated, 'It comes back to assessment and interpreting ... not just writing it down ... asking the right questions' (Focus Group 2 - Participant 3, District Nurse).

\section{Resources}

The provision of equipment was seen as essential for discharge. Equipment or care not always being available in the community was a concern and affected both hospital and community staff. Community staff described organizing discharge around the provision of equipment. Supply of dressings often caused the community staff diffi- culties. 'there . comes a point where it doesn't matter how good the discharge is... how well planned... how well it's communicated. When there is a lack of equipment ... or a service, the discharge process has to stop until it is sorted out' (Focus Group 3 - Participant 2, Occupational therapist). All the participants acknowledged that wards were extremely busy and lack of staff was discussed at length, one nurse spoke of her experiences: 'If you've got one named nurse for eight acute patients and if you then expect her 'to do a nice discharge too' ... when she has been working for ten hours ... its difficult, I certainly was too tired' (Focus Group 3 - Participant 7, Community staff nurse).

\section{Time}

There were two main elements to this theme. First, there was the pressure felt by professionals trying to get patients through the system. Patient 'throughput' at the expense of quality was identified in focus group two. Poor timing sometimes led to patients being referred to a team member at the end of their hospital stay, thus potentially compromising assessment and treatment. Secondly, there was the frustration of waiting for some bureaucratic parts of the discharge process to be completed. This was mainly associated with assessments and report writing required by social workers, to ensure placements were agreed and funded.

District nurses stated that they wanted to be more involved in patient home visits. Whilst the organizing and the multidisciplinary discussion during these visits could be time consuming, it helped them to assess and prevent long term problems. District nurses saw some visits as inappropriate and wasting time. These occurred when there had not been any discussion with them. For example, checking of healthy wounds when the patient was able to attend the GP's surgery and continual chasing of information that should have been forwarded by the hospital was emphasized as time consuming.

\section{Patient interviews}

Ten in-depth interviews were conducted, each lasting approximately one hour. Three major themes emerged from the patient interview data and provided a different perspective on the barriers described by professionals. Patients were con- 
cerned about reoccurrence of their illness, knowledge and the variability of the discharge process.

\section{Their illness}

When asked what their most important concern was following discharge, patients pointed to the possibility of recurrence of their illness, which may prevent them coping at home or lead to a return to hospital. This was regarded as personal 'failure' by patients. Whilst patients were happy to return home, they felt vulnerable and concerned about leaving the health care environment. Participants who were going into residential or nursing homes or going back to their own homes but receiving a lot of nursing input because of physical disability were particularly apprehensive. 'You don't really know what to expect... I suppose you take a leap of faith' (Participant 8). It was evident from the interviews that patients had very little opportunity to discuss their fears or concerns about their illness or how they would cope at home with health care professional. Two further themes to emerge from the data were knowledge and variability in the discharge process. These two themes echoed the issues that emerged in the professional focus groups.

\section{Communication of knowledge}

All participants said that they were happy with their discharge involvement, although some patients did not ask for information or did not understand information that they had been given. When a health or disease related discussion took place many patients did not question, or did not want to cause trouble, and so complied with the view of health care professions. The patients' lack of understanding appeared to reduce their control or 'power' over the process of discharge and sometimes patients did not then have the confidence to ask questions. One patient was commenced on an inhaler, 'The doctor prescribed it for me to go home on, I think he thought that I was already on one. He said I was asthmatic, I don't think I am but he said that I was' (Participant 9). The researcher asked if the patient knew how to use her inhaler, 'No, the girl upstairs is a student nurse and she keeps an eye on me ... and she showed me how to use it' (Participant 9).

However, other patients did have opportunities to participate in discussions about their health and were more aware of their diagnosis and medication than others. In contrast patients appeared to have more knowledge about the services or physical and domestic help they wanted, but not about the process of initiating them. Participant seven stated, 'I think that I did get what I wanted ... but I think you need to say what you want otherwise you could get what other people think is best... the doctor can then sort it out' (Participant 7)

\section{Co-ordination}

Variability of discharge processes due to different patient circumstances was recognized by participants who saw other patients being seen by different professionals before they could be discharged home. 'the lady in the green trousers came to see the lady next to me but she didn't come to see me, I don't think that I needed her' (Participant 1).

There was also a variety of opinions and knowledge about who organized discharge, ranging from the doctor, to the nurse, to the social worker. All except one of the participants had been in hospital before, one participant recognized how discharge arrangements differed from his previous stay by commenting, 'I feel that the discharge was more organised this time as I didn't have to wait for things ... it was better' (Participant 4).

Four participants felt their discharge had been delayed, two due to social services issues and two because further medical tests were considered necessary.

\section{Discussion}

In this study we have identified barriers in a particular setting to improving discharge practices. These include; lack of patient and professional knowledge about discharge, variability in the discharge process with professionals often not understanding each others' roles, and resources such as time and equipment being limited. The communication of information to both patients and professional colleagues is central to the barriers highlighted. Failures of communication and teamwork across the interface created difficulties in the coordination and continuation of care. These themes have to a varying extent been identified in previous studies in other hospitals. However, our study explored the barriers prior to the development of tailored interventions to overcome them and offers 
an approach for others seeking to employ more effective means of implementation. Thus, we found that professionals were able to describe barriers for which simple strategies could be selected. For example, educational interventions at a team level might increase understanding and assist with the implementation of guidelines. The findings indicate that the elements of the discharge process are interrelated and addressing one issue without considering others such as team dynamics and communication would be unlikely to lead to improvements for patients.

Barriers were identified at an individual level (e.g., verbal communication), at a team level (e.g., decision making) and an organisational level (e.g., policy on patient records). Improvements in discharge practice is likely to require attention at all levels. Therefore, it is likely that combinations of strategies with each component directed at overcoming specific, identified barriers would be more likely to succeed in changing discharge practice.

The methods used in this study have facilitated the collection of detailed information about the perceived barriers to discharge. But we have not been able to test the validity of the perceptions and cannot be certain which barriers are most important. Furthermore, some barriers may have been overlooked. Due to resource limitations, nonattendees from the focus groups were not followed up, although they may have identified other barriers. Carers were not included in the study, due to resource implications, also only one of the patients interviewed had a carer who lived with them. However, the identification of similar themes, such as variability in process and the perceived lack of knowledge/control in both the patient interviews and the focus groups help validate the findings. A combination of methods allowed for triangulation, which was adopted for the purpose of achieving completeness of data (Knafl and Breitmayer, 1989). The study will, however, have limited transferability as it includes a small number of participants, is based in one locality and there is an uneven representation from certain health care professional groups.

The focus group format might have led to an over-emphasis on team problems and alternative methods of data collection such as observation or questionnaires may have produced other results. Nevertheless the multidisciplinary team is central and therefore it may be appropriate to target inter- ventions to improve discharge at this level. The findings do indicate a culture in which the functioning of teams was assumed (Landefield et al., 1995; Rich et al., 1996) although previous discharge studies do not consider team education, and working relationships when discharge interventions are introduced. Interprofessional cooperation is not always effective and communication within and outside the team (across the interface) was perceived as having lower priority than patient 'throughput'.

The team is not often considered in complex interventions in the health service and while studies demonstrate the effect of a specified team member such as the 'discharge nurse' (Evans and Henndrick, 1993), the team and its constitution are not widely discussed in the discharge literature. The importance of team dynamics, how staff perceive change or if existing staff had received training is not a prominent feature of intervention studies in health services research. Whilst a major organizational change involving teams and working practices may seem appropriate, research so far has not examined the effect of combined strategies when trying to improve the discharge process.

\section{Conclusions}

The study has implications for future research. Alternative methods of identifying barriers to change should be evaluated and their role in designing tailored interventions explored in detail. With regards to improving the discharge process, future research should include the evaluation of a complex intervention at team level, designed to address explicitly identified barriers to discharge planning. The findings of this study suggest that interventions shown to be effective in one setting will need to be locality specific and adapted by professionals involved in the discharge process. Experimental studies to test the effect of complex interventions such as these are required.

\section{References}

Bull, M. 1994: Patients' and professionals' perceptions of quality in discharge planning. Journal of Nursing Care Quality 8, 47-61.

Congdon, J.G. 1994: Managing the incongruities: The Hospital 
discharge experience for elderly patients, their families and nurses. Applied nursing research, 7, 125-31.

Closs, J. and Tierney, A. 1993: Discharge planning for elderly patients. Nursing Standard 7, 30-33.

Department of Health 1989: Discharge Patients from Hospital. London: HMSO.

Department of Health 1992: The Patient's Charter. London: HMSO.

Department of Health 1994: Hospital Discharge workbook: a manual on hospital discharge practice. London: Department of Health.

Evans, L.R. and Henndrick, R.D. 1993: Evaluating Hospital Discharge Planning: Randomised Clinical Trial. Medical Care 31, 358-70.

Farren, E.A. 1991: Effects of early discharge planning on length of hospital stay. Nursing Economics 9, 25-30, 63.

Harding, J. and Modell, M. 1989: Elderly people's experiences of discharge from hospital. Journal of the Royal College of General Practitioners 39, 17-20.

Haddock S. 1994: Collaborative Discharge planning: Nursing and Social services Clinical Nurse Specialist 8, 248-52.

Jewell, S.E. 1993: Discovery of the discharge process. Journal of advanced Nursing 18, 1288-96.

Knafl, K.A. and Breitmayer, B.J. 1989: Triangulation in qualitative research: issues of conceptual clarity and purpose. In: Morse, J.M., editor, Qualitative Nursing Research Maryland: Aspen Rockville. 209-20.

Landefeld, C.S., Palmer, R.M., Kresevic, D.M., Fortinsky, R. H. and Kowal, J. 1995: A randomised trial of care in hospital medical unit especially designed to improve the functional outcomes of acute ill older patients. N Eng J Med 332, 1338-44.

Lockery, S.A., Dunkle, R.E., Kart, C.S. and Coulton, C. J. 1994: Factors contributing to the early rehospitalisation of elderly people. Health and social work 19, 182-91.

Lowenstein, A.J., and Hoff, P.S. 1994: Discharge planning: A study of nursing staff involvement. JONA 24, 45-50.

MacWilliam, C.L. and Wong, C.A. 1994: Keeping it a secret: the cost and benefits of nurse's hidden work in discharging patients. Journal of Advanced Nursing 19, 152-63.
Madsen, I. 1965: Report on Procedures on Discharge of patients from Hospital. London: Royal College of Nursing.

Mamon, J., Steinwach, D., Fahey, M., Bone, L.R., Oktay, J. and Klein, L. 1992: Impact of Hospital discharge planning on meeting Patients needs after returning home. Health Service Research 27, 155-75.

McWilliam, C.L., Sangster, J.F. 1994: Managing patients discharge to home, the challenges of achieving quality of care. Journal for Quality in Health Care 6, 147-61.

Meara, J.R., Wood, J.L., Wison, M.A. and Hart, M. 1992: Home from Hospital: A survey of hospital discharge arrangements in Northamptonshire. Journal of Public Health Medicine 14, $145-250$.

Miles, B.M. and Huberman, A.M. 1994: Qualitative Data Analysis. Sage Publications, London.

Naylor, M.D. 1990: Comprehensive Discharge Planning for Hospitalised Elderly: A Pilot Study. Nursing Research 39, 156-61.

Peet, S., Castleden, M., Jagger, C., Baker, R., Parker, S. and Hibbitt, M. 1997: Effective patient Discharge. Trent Health Authority: Final Report.

Rich, M.W., Gray, D.B., Beckham, V., Wittenberg, C. and Luthyer, P. 1996: Effect of a multidisciplinary intervention on medication compliance in elderly patients with congestive heart failure. Am J Medicine 101, 270-76.

Roberts, I. 1975: Discharged from Hospital. London: Royal College of Nursing.

Skeet, M. 1970: Home from Hospital. London: Dan Mason Nursing Research Committee.

Styrborn, K. 1995: Early discharge Planning for Elderly patients in acute hospitals. Scandinavian. Journal of Social Medicine 23, 273-85.

Tierney, A.J., Macmillian, M.S., Worth, A., Closs, S.J., King, C., Atkinson F.I. 1993: Discharge planning for elderly people going home from hospital: Experiences of patients and their carers. Report prepared for the Scottish Home and Health Department. Nursing Research Unit. Department of Nursing Studies. The University of Edinburgh.

Williams, E.I. and Fitton, F. 1991: Surveys of carers of elderly patients discharged from hospital. British Journal of General Practice 41, 105-8. 